\title{
Farmer innovation diffusion via network building: a case of winter greenhouse diffusion in China
}

\author{
Bin Wu $\cdot$ Liyan Zhang
}

Accepted: 4 January 2013/Published online: 27 April 2013

(C) Springer Science+Business Media Dordrecht 2013

\begin{abstract}
Farmer innovation diffusion (FID) in the developing world is not simply the adoption of an innovation made by farmers, but a process of communication and cooperation between farmers, governments, and other stakeholders. While increasing attention has been paid to farmer innovation, little is known about how farmers' innovations are successfully diffused. To fill this gap, this paper aims to address the following questions: What conditions are necessary for farmers to participate in FID? How is a collaborative network built up between farmers and stakeholders for this purpose? And what roles can government play? The above questions are addressed through analysis of the diffusion of winter greenhouse technology in China. A framework for analyzing a FID system is developed, and the conclusion is drawn that building mutual trust and collaborative networks is crucial for the success of FID. Furthermore, this network building can be broken down into various levels with different scales, speeds and consequences for FID: informal networks among farmers themselves, farmer-led networks, and government-facilitated networks. The success of government intervention depends upon building and enhancing the collaborative networks in which farmer leadership is crucial.
\end{abstract}

B. Wu $(\bowtie)$

School of Contemporary Chinese Studies, University of Nottingham, Jubilee Campus, Nottingham NG8 1BB, UK e-mail: bin.wu@nottingham.ac.uk

\section{Zhang}

Center for Innovation and Entrepreneurship, Tianjin University of Finance and Economics, 25 Zhujiang Road, Hexi Distract,

Tianjin 300222, People's Republic of China
Keywords Farmer innovation diffusion - Farmer leadership · Government intervention - Collaborative network building · Winter greenhouse diffusion · China
Abbreviations
DWG Dongwugou
FID Farmer innovation diffusion
NGO Non-governmental organization
SYZ Shanyuanzhu
WGD Winter greenhouse diffusion

\section{Introduction}

In the last three decades or so, the international community has paid increasing attention to farmer innovation, defined as any technology invention or improvement made by rural people in order to cope with the complexity of local resource, ecological, economic, and social conditions (Chambers 1983; Chambers et al. 1989; Biggs 1990; Reijnties et al. 1992; Rajasekaran 1993; Critchley et al. 1999; World Bank 2004; Wortmann et al. 2005). While the emphasis has been on the practicality of local knowledge and farmer innovation within the community, we know little about how farmer innovation can be successfully diffused to other rural areas with different ecological, economic, and social environments. The term farmer innovation diffusion (FID) in this paper can be defined as a process of diffusing farmer innovations to wider communities, which involves a process of building collaborative networks for communication and cooperation between farmers, governments, and other stakeholders such as agricultural extension staff and non-government organizations.

FID is usually achieved through informal farmers' networks, through private companies or through the public 
domain (e.g., public funding, media, agricultural extension agencies, government or non-government agencies), whether for commercial benefit or public good. In this paper we are concerned with FID by means of non-commercial channels, which brings farmer innovation into the discourse of local development and benefits wider communities. Special attention is given to the realization of diffusion through outside intervention, especially by government. Commercialization is a separate issue we will not touch on in this research.

The rationale of this paper is based upon the belief that many farmer innovations in one area have the potential to benefit the rural poor in other areas of the world who suffer similar difficulties. Due to many barriers (e.g., information, finance, and traditional production system), this diffusion process is often blocked to a certain degree. Encouragingly, there are many successful cases of FID via different channels, organizations or external institutions. In particular, we are concerned with the role of government intervention in rural China, where non-governmental organizations (NGOs) are underdeveloped and the agricultural extension system is weak in delivering its services to farmers ( $\mathrm{Hu}$ et al. 2009). While there have been many successful experiences in large-scale intervention and promotion of FID, including the case of winter greenhouse diffusion developed in this paper, little academic research has been conducted to explain why some of these interventions have succeeded and others failed.

To fill this gap, this paper aims to address the following questions: What are the conditions necessary for farmers to participate in FID? How is a collaborative network built up for this purpose? And what roles can and does government play? The above questions are addressed through analysis of the diffusion of winter greenhouse technology in China.

\section{Innovation diffusion and networks: a literature review}

FID across geographic, economic, and social boundaries involves factors such as public resources and government and non-governmental agencies. Despite the lack of literature addressing FID directly, there is much research that is relevant to the theme of this paper. From the perspective of communication and interaction between farmers and external stakeholders, relevant debates can be divided into four camps: innovation diffusion, technology choice, agricultural innovation systems, and actor network building.

Innovation diffusion as a part of the classic technology transfer model treats agricultural innovation diffusion as a process from scientific research institutes to farmers via extension stations (Röling 1988; Scoones and Thompson 1994; Roux et al. 2006; Williams and Woodson 2012).
Focusing on how, why, and at what rate a new idea or technology spreads among the members within a social system, Rogers (1962) poses a useful analytical framework. Not limiting himself to analysis of individual behaviors in technology adoption, he emphasizes the roles of communication channels, opinion leaders, and social systems on technology adoption. While Rogers' framework offers insight into the differences among community members in technology learning and adoption (Heffernan et al. 2008), the linear model has limitations when interpreting the phenomenon of farmer innovation (Biggs 1990; Ruttan 1996; Röling 1994). This is because the rural poor in the developing world are more likely to live in complex, diverse, and risk-prone environments (Chambers et al. 1989; Pretty 1995). As a result, they may face serious constraints from not only complicated ecological, economic, and social environments, but also insufficient information and poor capacity to bear any waves and shocks from uncertain market or environmental conditions (Wu 2003).

Taking into account the complexity and diversity of rural livelihood systems in the developing world, innovation diffusion can be viewed as a process of technology choice. Schumacher (1973) emphasizes "appropriateness to local people" as a primary factor to consider. A key question arises here: who makes decisions on adoption or rejection of a new technology and what factors influence their judgment about the appropriateness of technology? Disagreeing with the assumption of rational farmers used in classic economics, Abrahamson (1991) argues that potential adopters are often unable to assess the technical efficiency of an innovation when they make a decision. Instead, he distinguishes three alternative diffusion perspectives: (1) the fad perspective in which members of a group imitate each other in terms of technology adoption or rejection; (2) the fashion perspective, in which influential organizations or individuals outside ("fashion-setters") are imitated by members of the adopter group; and (3) the forced-selection perspective in which a number of outside organizations or individuals have the power to select technologies and force the members of the group to accept them (Sneddon et al. 2010).

The fad-fashion theory offers insight into the initial stages of FID, which can be distinguished into three types: farmer leadership within the community; NGOs or other intermediate organizations; and government intervention. Taking the diffusion of organic agriculture in Kenya and beyond as an example, Goldberger (2008) explains the role of NGOs as a "boundary organization" to build a strategic bridge for communication, negotiation, and collaboration between farmers, international donors, national and local governments, and research institutions. While the NGOs become the center of innovation diffusion, according to 
Igoe (2003, p. 881), a problem facing many internationally sponsored NGOs is "NGO leaders become gatekeepers between western donors and the communities that they wish to assist." Similarly, Williams and Woodson (2012) view the role of NGOs as strong innovators and the role of government as innovator through technological appropriation. With an absence of NGOs in China, much research (Wang et al. 2009; Liu et al. 2011) examines the effectiveness of government intervention on agricultural innovation diffusion and indicates a deficiency in effective communication with farmers. Given the importance of effective communication and shared understanding between farmers and external stakeholders, a question arises regarding the role of farmer leadership.

Amending the narrow technology transfer model, the agricultural innovation systems (AIS) perspective concerns how society generates, disseminates, and utilizes knowledge for poverty alleviation and livelihood security in the developing world (Leeuwis and Van den Ban 2004; Rivera and Rasheed Sulaiman 2009; Lundvall 2010). The World Bank (2006, pp. vi-vii) for example, defines an innovation system as "a network of organizations, enterprises, and individuals focused on bringing new products, new processes, and new forms of innovation into economic use, together with the institutions and policies that affect their behavior and performance." Based upon systems principles, an analysis framework has been proposed to reveal "complex relationships among diverse actors, social and economic institutions, and technological and institutional opportunities" (Spielman 2006, p. 42). In relation to FID studies, for instance, Biggs (1990) identifies multiple sources of innovation, including: users and practitioners (e.g., researchminded farmers, innovative research practitioners, researchminded administrators), innovations from NGOs, innovations from private corporations, and innovations from extension agencies. Furthermore, Pant and Odame (2006) illustrate a tripartite partnership model comprised of public sector, for-profit private sector and non-profit private sector, with the informal sector located at the center. While this approach accommodates more factors to aid understanding the causes for and consequences of agricultural innovation diffusion, farmers are still left in a marginal position due to the hierarchical nature of its structure. As a result, the contribution of farmers to agricultural innovation is likely to be underestimated. Furthermore, with an emphasis on knowledge sharing and intra-organizational links, this approach seems to underestimate the differences and communication barriers between farmers and other stakeholders due to differences in values, interests, and attitudes.

Actor innovation networks originally focused on the study of scientific research methodology, emphasizing the nature of the interconnection and interaction between nature, technology and society (Schneider et al. 2012). With respect to sustainable resource management, a "social learning" perspective has emerged and is becoming increasingly popular, in which local or indigenous knowledge is critical for scientists and professionals (Leeuwis and Van den Ban 2004; Dewulf et al. 2005; Eshuis and Stuver 2005; Risk et al. 2007). Viewing nature as "an active, lively, constructive, and relational presence, rather than only as metabolism" (Goodman 2001, p. 190), actornetworks "consist of not only human, but also non-human actors such as equipment, animals, natural resources, texts and norms" (Schneider et al. 2012, p. 244). As a result, "scientific and technological innovation is conceptualized as the result of networking building between heterogeneous actors" (Schneider et al. 2012, p. 244). Not limited to indigenous knowledge, the role of farmers has been significantly extended in this perspective as they have become one of the most important actors in building the communication networks between professionals (scientists and agricultural extension experts) and nature systems (Wu and Pretty 2004). Lorentzen (2010) calls for research on the connection between external technology transfer and local innovation diffusion, and on community or user-driven innovation. Regarding the impact of the rise of global food safety standards and environmental sustainability, PerezAleman (2012) emphases the necessity of increasing networks between farmers, government and nongovernmental organizations for local knowledge building. However, the actor-network theory seems to pay little attention to political factors and the role of government, which determines the space for local farmers in technology choice and network building.

Having briefly reviewed the relevant literature, we can draw the following conclusions concerning progresses and research gaps in innovation diffusion studies. First, despite different angles and perspectives, it is rather common for all schools of thought to recognize the importance of communication networks for innovation diffusion. Second, it is also no different to acknowledge the importance of farmer participation in innovation networks, although different scholars may have different opinions over what roles farmers can play in the network. Third, less research has been done into how a collaborative network is built and what the relationship is between farmers and government in the process of innovation. Given the fact that there is strong government intervention in innovation diffusion in China, the rest of this paper will focus on network building and the role of government intervention.

\section{Conceptual framework}

By bringing relevant literature together, this section aims to set a conceptual framework for field observation and data 
analysis of FID. With respect to conditions underpinning FID, in particular, we pose the following elements and relations between them for the purpose of interpreting FID: technology appropriateness, government intervention, farmer leadership, and collaborative networks.

First of all, not all but only a few farmer innovations may have the potential to be diffused to other locations. Sharing Schumacher's perspective (1973), we pose technology appropriateness as an important condition for FID. Based upon the research findings on farmer innovation in China's marginal areas ( $\mathrm{Wu} 2003)$, the term technology appropriateness in this paper contains two aspects: (1) the interface of a "new technology" with the local farming production system and learning capacity; and (2) suitability to the local market and farmers' needs for technology development. The former refers to the gap between new and old technology and the coping strategy adopted by local people, while the latter is related to farmers' perceptions or calculation of costs, benefits, and risks.

Following the suggestion of the fad-fashion theory, we are concerned with the influence of external factors, in particular government intervention, on the farmer's adoption of a new technology. Government intervention here refers to the role of government in selecting, promoting, pursuing, and supporting farmers to accept and adopt a farmer innovation on a larger scale and/or within a short time-scale. The motivation for government intervention may vary: for instance, the needs of the local economy and farmer income growth, expectations or judgments about technology appropriateness, and political pressure. As a key variable for FID, government intervention can be measured in two ways: commitment to the FID process, and capacity in terms of technology selection and mobilization of various resources (including administrative, economic, and political measures).

Parallel to external government intervention, according to fad-fashion theory, equally important is internal influence on farmers' decision to adopt or refuse a new technology. Farmer leadership is an important variable for FID not only because individual farmers are not homogeneous in terms of understanding and taking the opportunities from the outside, but also because they may not be able to communicate directly with external stakeholders and governments without their representatives. With a focus on FID via the public domain, farmer leadership becomes even more important in dealing with government intervention and developing meaningful and efficient communication with community members for collective actions. Similar to Rogers' (1962) “opinion leader," farmer leadership is not necessarily an innovator or village administrative leader although such a role may help him/her to reduce potential resistance significantly. More important is that he or she has a good understanding of the value of the new technology; communication skills required to access public resources and reduce potential risk; a strong commitment to the majority of, if not all, community members for their share of opportunities and potential benefits; and, most importantly, full trust and respect from community members.

Neither government intervention nor farmer leadership may be enough for FID unless a collaborative network is taken into account because FID cannot be achieved without a channel or base to carry out communication, interaction, and cooperation among farmers, and between farmers, governments, and other stakeholders. Learning from the actor innovation network perspective, collaborative networks become a crucial condition or variable for FID. Differently, the collaborative network here emphasizes mutual respect and trust for effective communication and interaction between farmers and stakeholders. It cannot be narrowly defined as the communication and mutual trust between farmer leaders and governments, which is not enough to mobilize or pursue the majority of community members to participate. Essentially, a collaborative network is a network of mutual learning, understanding, and trust, leading to information circulation, sharing, and feedback among farmers themselves and between farmers and external participants. In this sense, FID can be viewed as a process of network building for collective actions toward local technological, economic, and social changes.

The above elements are interwoven and interact. Bringing them together, a triangular model for conditions of and relations behind FID can be illustrated as in Fig. 1.

The potential and explanatory power of the FID system model can be illustrated and tested through a case study of winter greenhouse diffusion (WGD) in China. We have selected WGD for three reasons. First, this is typical of a farmer innovation that started in one place and has subsequently been widely diffused and adopted, in this case by millions of farmers in China throughout two decades. Second, this case involves three locations across different environments in three provinces of North China. Third, all

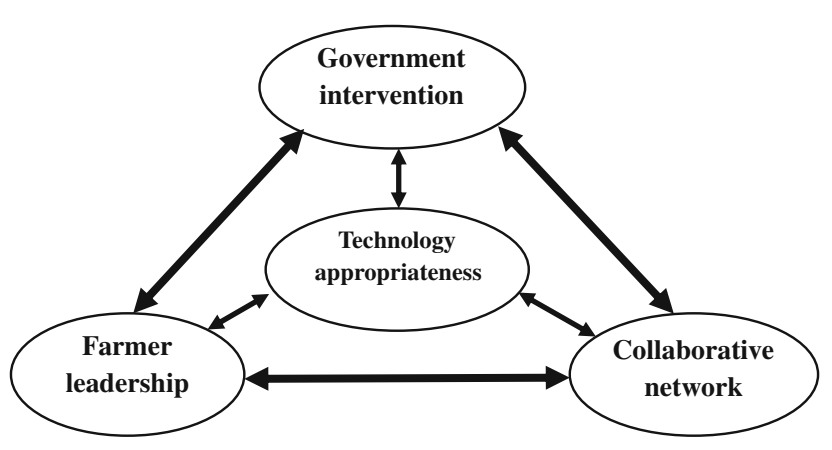

Fig. 1 FID system: an analysis framework 
of the above cases involve government intervention in different ways with different consequences for WGD.

\section{Fieldwork settings: historical context for government intervention}

Government intervention in agricultural innovation in the People's Republic of China can be traced back to the People's Commune regime established in the late 1950s. While all rural labor was assembled for collectivized agricultural production, without any space for individual farmers, the promotion of agricultural innovation was listed as an important objective for rural development.

In the late 1960s and early 1970s, an agricultural extension network was established nationwide that matched the three-tier agricultural management system (Commune, Brigade, and Production Team). This was comprised of four tiers: an agricultural research and extension centre at the County level, an agricultural extension station at the Commune level, a farmer innovation group at the production brigade level and individual farmer technicians at the production team level (Delman 1991).

Predominated by Chairman Mao Zedong's philosophy that the people are masters and innovators of social development, a bottom-up paradigm was imposed. As a result, the experience of farmers was highlighted which was equally, if not more highly, valued as the scientific knowledge from professionals. In practice, all professionals, including agricultural researchers, university teachers, and students, were required to stay in the countryside for a certain period in order to familiarize themselves with local knowledge and farmers' production practices. The purpose of professional participation in the countryside was to foster a mutual learning process and bring experienced farmers, relevant professionals, and government officials together toward best solutions and full use of local knowledge, resources, and opportunities.

Within this highly political atmosphere, it may be questioned whether the above model was effective in practice. While farmers were indeed brought to the center of agricultural innovation, less attention was paid to agricultural research and the opinions of professionals, which impeded the development and diffusion of modern agricultural technologies.

A fundamental change has happened since the late 1970s when rural economic reform led to a replacement of the People's Commune regime with a Household Responsibility System. The new system offered more freedom for farming households to make their own decisions on agricultural production and labor allocation. It led to a breakdown of the established agricultural extension network, forcing local government to explore new ways of extending agricultural technology.
Unlike Chairman Mao, Deng Xiaoping put emphasis on scientific research and the application of modern agricultural technology. This represented a paradigm change in which farmers were no longer in equal partnership with professionals. Instead, they became marginalized in the modern agricultural innovation system. Agricultural scientists and researchers are at the top, agricultural extension agents in the middle and farmers at the bottom.

Reflecting upon the change in the agricultural innovation paradigm, there have been a series of adjustments in agricultural innovation policies. At the national level, priority has been given to agricultural research and development into high technology agriculture for securing grain growth in order to cope with the challenges of an expanding population. At the local level, commercial agriculture and non-agricultural employment were prioritized by local authorities for economic growth. Thirdly, facing a breakdown of the original agricultural extension network, local governments at county and township levels took responsibility for agricultural extension through a combination of administrative, economic, and fiscal measures.

Even so, farmer innovation has not been entirely ignored by the Chinese government, in particular local governments. There are many valuable practices, such as the case discussed in this paper. To understand the diffusion process, fieldwork was conducted by the authors in three places, Wa Fangdian in Liaoning Province, Shouguang in Shandong Province, and Zhidan in Shaanxi Province, in the mid-1990s and late 2000s respectively (see Fig. 2). Qualitative research methods were used including field observation, collection of historic information, and in-depth interviews with key informants within villages and local governments.

Our fieldwork in the three counties was undertaken based upon different sources, and at different times. The fieldwork in Wa Fangdian and Shouguang was undertaken in 2008 when we learned from media reports about this case. It started from a visit to Shanyuanzhue Village within Shouguang County, the center of large-scale FID. This trip led to another trip to visit to the innovation source in Wa Fangdian, Liaoning Province, to learn about the technology's invention and early diffusion. The fieldwork in Zhidan, a poor county in north Shaanxi, was taken separately by the first author in the mid-1990s (Wu 2003).

\section{A narrative of winter greenhouse diffusion}

The conditions of FID and the role of network building can be illustrated by the case of WGD. This innovation was started in the mid-1980s by a few farmers in Wa Fangdian in Liaoning Province. It was later transferred to Shouguang 
Fig. 2 Location of case study

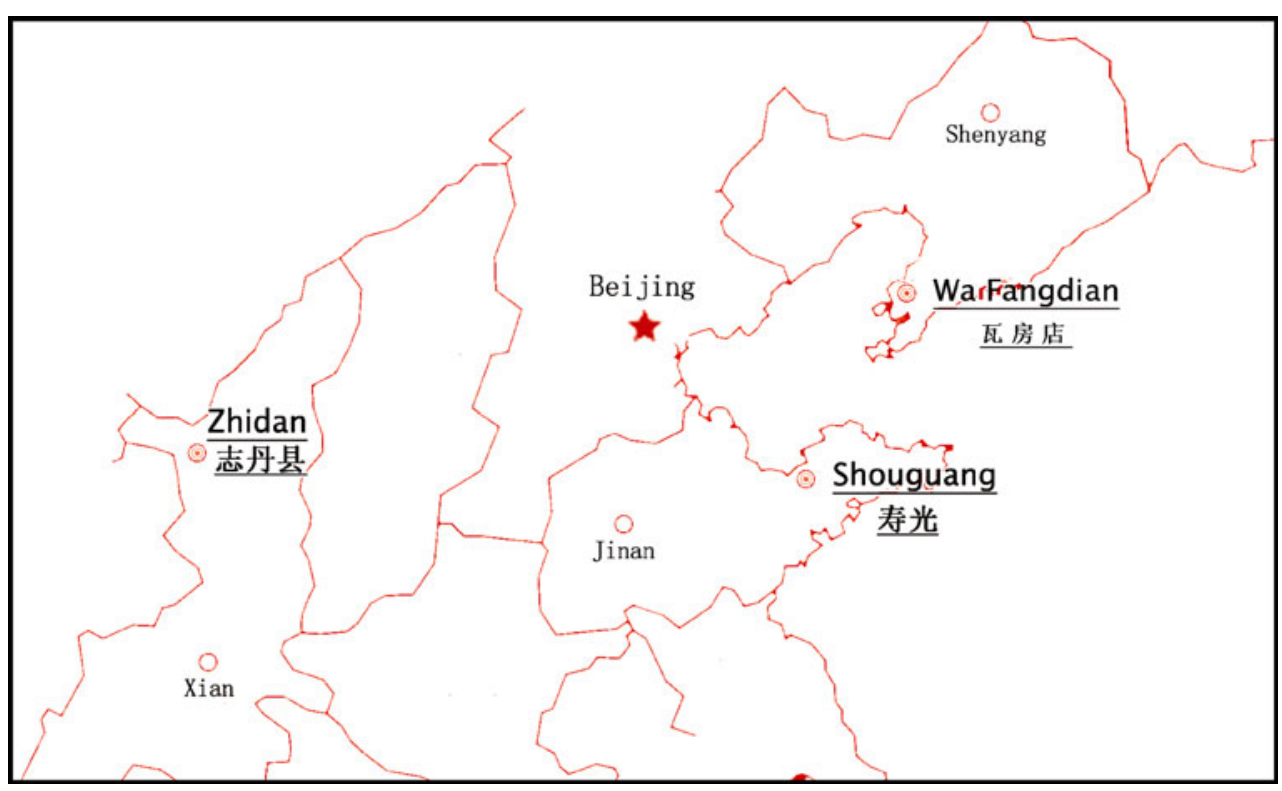

County in Shandong and then disseminated widely in China. This section provides the background of winter greenhouse innovation and diffusion in different places based upon our field studies.

Background of winter greenhouse innovation in Wa Fangdian

The winter greenhouse for cucumber production without supplementary heating was successfully introduced in 1985. The key technology breakthrough was made by two young farmers, Tao Yonghua and Li Yongqunin, both in Taotun village, $1 \mathrm{~km}$ from Wa Fangdian City center.

Greenhouses for vegetable production was not totally new to local farmers as glass greenhouses had been adopted by a few collective Brigades in the 1960s in this area, which depended upon coal heating for vegetable production in winter. Replacing glass by plastic covers, the so-called "summer greenhouse" appeared in this area in the 1970s as it could be used in summer only without supplementary heating. Farmers could gain benefits from the summer greenhouse as they could earn more money via planting and supplying vegetables for urban residents a few weeks earlier than those who did not have this greenhouse. Furthermore, a significant technology innovation, grafting for enhancing cold-resistance capacity, was made by a farmer in Zhang Shanzui Village in 1981, which made it possible to plant and harvest cucumber in late March, 2 months earlier than conventional methods. Based upon the above technological progresses in the early 1980s, Tao and Li made another breakthrough, successfully building a plastic-covering greenhouse for cucumber production throughout winter without any heating device. Bearing in mind the cold winter in this region $\left(-23{ }^{\circ} \mathrm{C}\right.$ in the coldest winter of the 1980s), this innovation involves many technology improvements and synthesis: greenhouse architecture structure (e.g., the thickness and height of the rear wall of the greenhouses), direction of the house for maximum absorbing of sunlight and avoidance of strong winds, selection of suitable materials and control of inside temperature, etc.

The successful application of the winter greenhouse for cucumber production throughout the cold winter without any heating assistance is a symbolic technological breakthrough. This is because cucumber is more sensitive to temperature and difficult to cultivate in cold weather. Not limited to cucumber production, the winter greenhouse was soon applied to other varieties of vegetables, such as tomatoes, eggplants, etc., then to flowers, fruits, aquatic products, livestock, and poultry. The winter greenhouse for vegetable production not only enriched the Chinese people's winter vegetable basket, but also increased the farmers' income significantly. For instance, Tao earned more than 10,000 Yuan from his winter greenhouse only in the first year of his innovation, compared with less than 1,000 yuan per capita as the net annual income of rural residents in this region.

\section{Autonomous diffusion in Wa Fangdian}

Despite the successful innovation made by $\mathrm{Tao}$ and $\mathrm{Li}$, there was no follow up within the village for many reasons. First, the local government planned to reclaim their land for urban use soon so were reluctant to make any investment on it. Second, it was quite easy for local farmers to find non-farm employment opportunities with similar income to vegetable production. Third, compared with non-farm employment, winter greenhouses require hard 
work (for rolling up and putting down straw curtains), experience and techniques in vegetable production, and more importantly a large amount of investment, around 5,000 yuan (for the costs of plastic covering sheet, construction materials such as wood, bricks, cement). Such large investment was equivalent to the annual income of a high-income family in this area, a high barrier for villagers.

The route of the innovation diffusion in Wa Fangdian can be seen from Fig. 3 .

\section{Large-scale diffusion in Shouguang}

The WGD was slow within the boundary of Wa Fangdian until 1989 when Shuoguang County government became involved and took serious steps to promote WGD. In history, Shuoguang has had a long tradition for vegetable production. Compared with Wa Fangdian, climate conditions in Shouguan have also much better for vegetable production as its average temperature in winter is $6-7{ }^{\circ} \mathrm{C}$ higher than Wa Fangdian.

The information on winter greenhouse innovation arrived in Shanyuanzhu (SYZ hereafter) village in 1988 when a village member went to Wa Fangdian to purchase cucumbers for local distribution. This raised the interest of Wang Leyi, head of the village. He invited the innovator, Tao, to provide teaching and technical support for a WGD project in SYZ. As Tao did not accept this invitation, his neighbor, Han Yongshan, a young farmer took this

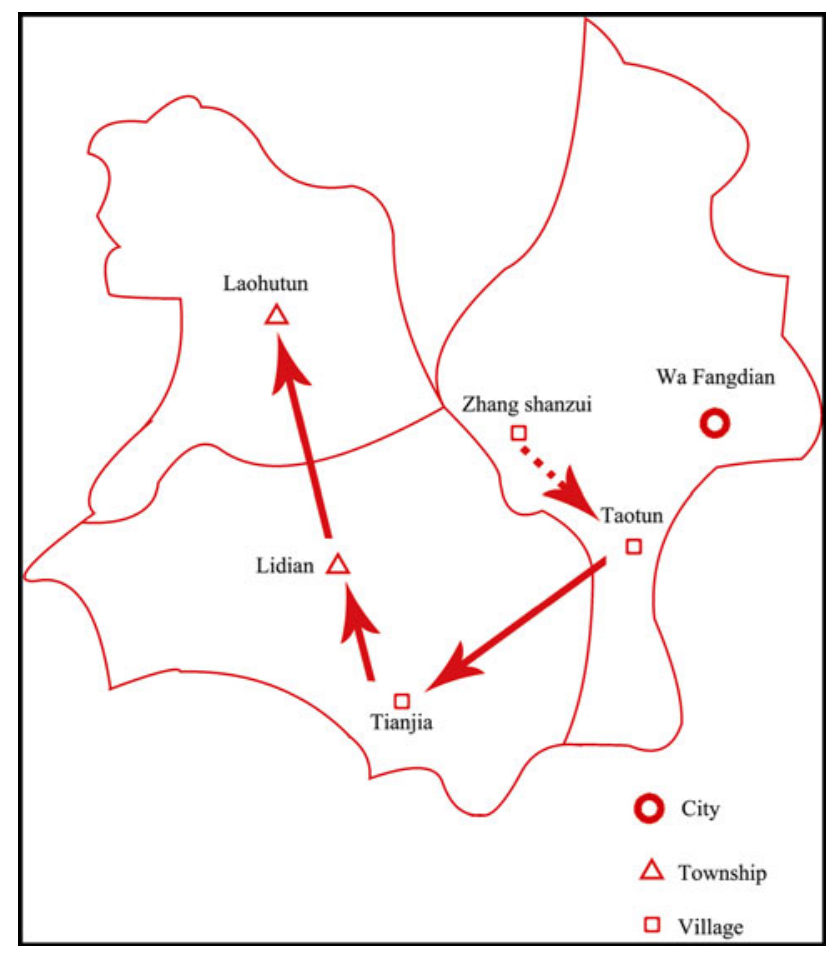

Fig. 3 The route of winter greenhouse diffusion in Wa Fangdian opportunity and moved to SYZ for demonstration and technological support with Wang.

Initially, no villagers were willing to join this project due to large investment required. Wang mobilized 17 village communist party members to join this project. In a joint effort with Han and with full support from the county government, all participants were successful in adopting this innovation by the end of 1989 and many households earned over 20,000 Yuan, more than double that of those who did not join.

Seeing the success, Shouguang county government decided to diffuse this technology in the county in 1990. A steering group was established and headed by the county governor. Wang and Han were invited to be technical consultants, in charge of communication with all participants countywide to sort out technical issues. As a top priority of the county development project, the government mobilized a concerted political effort, which required all township governors and village heads to sign a responsibility contract to ensure the success of WGD in their controlled territory. Meanwhile, the county government provided different support for this project, including adding irrigation systems to secure water supply and supporting animal husbandry for manure supply. As a result, a total of 5,130 greenhouses were successfully established in the year and average household earnings from vegetable production rose as high as 15,000 yuan.

The success of government intervention in Shouguan attracted the attention of both local and national media, leading to a rapid spread of winter greenhouse technology beyond Shouguan and the provincial boundary. Since then, many government delegations nationwide and leading political figures, including President Hu Jintao (in 2005), have visited SYZ Village and Shouguang County, and it has become highly regarded in the role of government intervention in FID. Meanwhile, Shouguang has become a national diffusion center of winter greenhouse technology, as many farmer technicians were invited by local governments nationwide to provide technical consultation and services.

Uneven diffusion in Zhidan, north Shaanxi

The successful experience of WGD in Shouguang has greatly encouraged local governments nationwide to learn from Shouguang in government intervention for FID. This is particularly true for those poor counties, including Zhidan County, where the government viewed intervention in FID as an important means for local economic development and poverty alleviation. This was an important reason why the WGD was selected as a part of the inter-provincial cooperation between Shaanxi and Shandong under the umbrella of the national poverty alleviation program. As a 
result, a farmer technician from Shandong was selected and sent to Zhidan as a consultant for WGD.

Bearing in mind the complexity of local environments, economic development, and farmer learning capacity, not all government interventions were successful. In fact, there were many unsuccessful cases. The story below of WGD in Zhidan shows the unevenness of government intervention in the poor areas of China (Wu 2003).

Zhidan is a located in north Shaanxi (see Fig. 2), which is covered by numerous hills and gullies. As a transitional area between agriculture and animal husbandry, traditional farming systems with the feature of over-cultivation on slopes had caused serious environmental consequences such as soil erosion. In addition, Zhidan was nationally recognized as a poor county where over $30 \%$ of the population was below the national poverty line in the mid1990s when our fieldwork was conducted. To cope with rural poverty and soil erosion in Zhidan, the local government emphasized agricultural innovation and WGD was one of the government projects in the early 1990s.

Like many agricultural extension projects in Zhidan, however, there was strong resistance to WGD in a number of the selected villages because of past experiences with cases of failed government projects. To remove this resistance, the government recruited labor forces from outside to cut down live crops in the targeted area and also provided financial subsidies to cover the costs of the materials for building the greenhouses. Three years later, unfortunately, most of greenhouses had disappeared. The failure, according to local informants, was related to many factors. First, the new technology was too complicated for local farmers who were used to the traditional farming system with little external input and cropping management experience. Second, the invited consultant knew nothing about the local environment and could not offer good advice. Third, there was not a stage of local experimentation and demonstration before wide diffusion. Finally, participating farmers were unable to make profits due to a limited local market and the small scale of vegetable production.

The exception was one village, called Dongwugou (DWG hereafter), $8 \mathrm{~km}$ away from the county seat, in which most of the winter greenhouses are still active and which has become a base of vegetable production for urban residents. To understand why the WGD has been successful in DWG, an investigation was conducted in the village ( $\mathrm{Wu} 2003)$.

Before the 1990s there were only four households in DWG involved in vegetable production of a few crops (e.g., potato, Chinese cabbage, radish, etc.). Surplus labor flowed into non-farm areas. The turning point for vegetable production in DWG was the introduction of greenhouse farming in 1993, when the county government decided to develop a winter greenhouse for vegetable production in a number of villages in valley areas, including DWG. Unlike other villages, the majority of winter greenhouses have survived. A factor contributing to the successful adoption in DWG was the existence of summer greenhouse before the introduction of the winter greenhouse. Furthermore, DWG continued to develop and utilize the winter greenhouses to raise seedlings to supply to summer greenhouse and non-greenhouse producers, which benefitted both sides. During one long winter, the users of vegetable seeds came to the winter greenhouse to contribute their labor for raising seed on the one hand, and exchange cropping techniques and experience on the other. By 1997, there were, in total, 10 households engaging in winter greenhouse production, 20 in summer greenhouses, and another 20 without greenhouses. Meanwhile, about 20 households in DWG were involved indirectly with service activities, such as the delivery of organic manure from the urban areas to the vegetable fields.

The success in DWG cannot be separated from the role of Wang Jianbao who acquired a good reputation for many innovations in Zhidan. He was the first adopter of the summer greenhouse in the county and the first supplier of vegetable seeds through his winter greenhouse. Equally important was his social capital and personal characteristics, such as his kindness and lack of self-aggrandizement, which provided a sound social basis for technology learning and diffusion.

\section{Case analysis and discussion}

The previous section has outlined the process of WGD in three locations: technology invention and autonomous diffusion in Wa Fangdian, large-scale diffusion in Shouguang, and uneven diffusion in the poor county of Zhidan. Despite great variety in terms of geographic, economic, and technological environments, some common elements and different features can be analyzed and compared through our analytical framework explained before. Relevant research findings can be summarized as follows.

Differing from Rogers' model of linear innovation diffusion, FID cannot be fully understood unless the complexity and diversity of local environments (broadly ecological, economic, and social conditions) are taken into account. For this purpose, we use "appropriateness of technology" (Schumacher 1973) as a condition of FID in order to reflect the interface of an innovation with local technical systems and farmers' needs. The appropriateness of technology can be used to interpret the reason why the winter greenhouse technology was not adopted by other members within Taotun, the home of the invention, where non-farm employment dominated. It was also an important factor responsible for the difficulty of adopting this technology in Zhidan, due to the domination of traditional 
farming production that was based upon extensive use of slope land with little labor and fertilizers inputs. Nonetheless, the cases of autonomous diffusion in Tianjia and other villages in Wa Fangdian and group learning in DWG, Zhidan show the importance of an "intermediate technology," the summer greenhouse, which provided the foundation for the successful adoption of the winter greenhouse. With respect to the successful experience in Shouguang, this confirms a conclusion drawn by $\mathrm{Wu}$ (2003, pp. 142-143) that the appropriateness of technology is not an absolute or constant, but a variable, which varies with local environments or conditions in receiving communities.

Technology appropriateness, however, does not necessarily secure individual farmers' participating in FID due to many constraints such as information, risk, and experience. Similar to "opinion leaders" in the innovation diffusion (Rogers 1962) or fad perspective in the fad-fashion theory (Abrahamson 1991), we pose "farmer leadership" to interpret the large-scale WGD in Shouguan which was difficult to imagine without Wang Leyi, whose success in his village won the trust and respect of large numbers of farmers. The same was true for the case of Dongwugou in Zhidan where Wang Jianbao and his winter greenhouse became a center of "group learning" and cooperation despite poor external innovation environments. Different from the expectation of either classic innovation diffusion or fad-fashion theory, however, the farmer innovator is not necessarily a farmer leader in FID. Tao Yonghua in Taotun, for instance, was a great innovator but did not become a strong leader in WGD. He played the role of consultant for technical advice but refused to organize and pursue farmers in his village or wider communities, including the opportunity provided by Shouguang. This is one of the reasons why WGD in Wa Fangdian was slow and limited to a few villages compared with the huge impact in Shouguan. A conclusion can be drawn from the above comparison: the stronger the leadership existing within a rural community, the larger the scale of farmer participation in FID.

Farmer leadership, similar to the appropriateness of technology, may not be enough for large scale FID unless the government becomes involved and makes a positive intervention. This is partly because small farmers in China are scatted under the current Household Responsibility System, and partly because the government controlled or monopolized public resources (e.g., finance and agricultural production elements) in the past, which can be used for disseminating relevant information and reducing market risks. In the case of WGD, strong government intervention can be found in Shouguang where political mobilization, technical and infrastructure support, and inter-governmental coordination jointly ensured successful diffusion within a short period. This is in contrast to the weak, almost non-intervention from the Wa Fangdian government. Zhidan is an example intermediated between the two, where the government introduced an expert from Shandong Province and took administrative means to initiate the process without a field experiment or demonstration stage. Filling the knowledge gap in innovation diffusion studies, this paper draws attention to the roles of government intervention in FID, which varies with other conditions. Under favorable conditions of appropriate technology meeting to common needs of farmers, government intervention becomes necessary and important for the large-scale participation of local farmers in FID.

Our empirical study confirms the actor network theory in terms of communication networking, social learning process, and the role of farmers as a key stakeholder. It shows, furthermore, the core element behind FID is mutual trust between farmer leaders and other community members and between farmers and local governments. In the case of Wa Fangdian, despite no formal communication existing between farmers and government, the existence of informal social networks among farmers was responsible for innovation diffusion across village boundaries. In Shouguang, the collaborative network was initiated by Wang Leyi, who introduced the external expert, and contacted the county government for support. Taking this opportunity the government had not only mobilized all county resources to participate but gave high regard to Wang and invited expert, Han, to lead the project, resulting in enhancing the collaborative networks. It was the network building that provided a sound foundation for mobilizing massive farmers' participation in such a short period. By contrast, there was no trust between farmers and local government in Zhidan (Wu 2003) due to so many failed cases of agricultural extension in the past, and also no time to build mutual trust between local farmers and external experts or the government. Likewise in the case of $\mathrm{Wa}$ Fangdian, an informal collaborative network existed in DWG village, which was further enhanced in the process of WGD. Among many other conditions and factors, a collaborative network provides a foundation for successful FID. In other words, FID can be viewed as a process of collaborative network building in which mutual respect and trust between farmers, and between farmers and stakeholders, have been stabilized, developed, and enhanced.

Three types of collaborative network building emerge from this paper, which have different impacts on FID:

1. Informal networks built by farmers themselves. This means that there is neither farmer leadership, nor government intervention or public resources involved, resulting in small-scale and/or low-speed FID. This can be applied to a large number of cases in Wa Fangdian.

2. Farmer-led networks farmer leadership exists or emerges in the process of FID, which may not only 
bring interested farmers together but also attract government support and public resources. This is suitable for the case of DWG village in Zhidan.

3. Government-facilitated networks, in which the government's full commitment is matched with proper public resources and strong farmer leadership, to develop and enhance mutual trust, effective communication, and productive cooperation among and between farmers, governments, and other stakeholders for large-scale or high-speed FID. This is the case of Shouguang.

The four conditions above, however, are interwoven, which determine the success or failure, as well as the scale and speed of a FID. The case of WGD has demonstrated the explanatory power of the FID model described in Fig. 1. By bringing many elements from appropriate technology, fad-fashion, and actor network theories together plus government intervention, the FID model nonetheless offers an alternative interpretation on the FID phenomenon in China, and perhaps other strong central authoritative economies, vis-à-vis classic innovation diffusion.

\section{Conclusions}

This paper aimed to reveal the various conditions of farmer innovation diffusion (FID) within an environment of strong government intervention or control. Based upon a critical review and synthesis of relevant literature, a framework for FID analysis has been established, which was applied to a case of WGD in three locations of China: Wa Fangdian, Shouguan, and Zhidan. A number of research findings and conclusions can be drawn.

First, FID should not be understood merely as a process of individual farmers' technological choice, as classic innovation diffusion theory suggests. This paper has identified four factors that influence farmer's decision-making: the appropriateness of the technology to local environments, farmer leadership, government attitude and commitment, and collaborative networks among farmers and between farmers and governments. If any of these elements is missing, FID is constrained.

Second, FID is largely dependent upon a process of collaborative network building among farmers and between farmers, government, and other stakeholders. This process can be divided into three types: informal networks built by farmers themselves, farmer-led networks, and government-facilitated networks. Different types of network building are responsible for different scales, speeds, and consequences of FID. Building up mutual trust and facilitating effective communication between farmers and stakeholders is therefore crucial to understanding the process and consequences of FID.
Third, based upon the successful farmer innovation practices, government plays an important role in formalizing, facilitating, and scaling-up the collaborative network, leading to an acceleration of FID on a large scale and benefitting wider communities. It is crucial for the government to support farmer leadership and promote collaborative network building, which influences the success or failure of government invention.

Fourth, it is important to note the timing of the WGD in China. In the late 1980s and 1990s, when public resources were limited and tightly controlled by the government, few private resources were involved. Since then the FID environment in China has changed significantly, which gives more space for other agencies, both commercial (e.g., agribusiness companies) and non-commercial (e.g., various NGOs), professional (e.g., agricultural extension institutions), and non-professional (e.g., Internet users), to become involved. Consequently, an amendment is inevitably required when the analysis framework used in this paper is applied to the cases of FID via other channels or government intervention since the 2000s.

Finally, the conditions of FID presented in this paper are not necessarily limited to China, but may be appropriated for other countries with strong government control. An international comparison could be beneficial for not only improving government intervention and distribution of public resources, but also promoting collaboration between government, non-governmental actors, and farmers.

Acknowledgments It is acknowledged that this research is sponsored by IDRC, Canada, and the United Kingdom Research Councils (NERC and ESRC) and Government (DFID) under the ESPA program (Ecosystem Services and Poverty Alleviation in the Developing Countries). Special thanks are given to Tao Yonghua and Sun Xiaofeng for their information and support for our fieldwork in Wa Fangdian. We are grateful to Professor Mike Parnwell and Dr. Cong Cao for constructive comments, and to Jared Collins for proofreading.

\section{References}

Abrahamson, E. 1991. Managerial fads and fashions: The diffusion and rejection of innovation. Academic Management Review 16(3): 586-612.

Biggs, S.D. 1990. A multiple source of innovation model of agricultural research and technology promotion. World Development 18(11): 148-1499.

Chambers, R. 1983. Rural development: Putting the last first. New York: Longman S \& T.

Chambers, R., A. Pacey, and I.A. Thrupp (eds.). 1989. Farmer first: Farmer innovation and agricultural research. New York: Longman $\mathrm{S} \& \mathrm{~T}$.

Critchley W.R.S., R. Cooke, T. Jallow, S. Latfleur, M. Laman, J. Njoroge, V. Nyagaha, and E. Saint-Firmin. 1999. Promoting farmer innovation: Harnessing local environmental knowledge in East Africa. RELMA Workshop Report Series No. 2. Nairobi: RELMA. 
Delman, J. 1991. Agricultural extension in Renshou County, China: A case study of bureaucratic intervention for agricultural innovation and change. Aarhus: Institute of East Asian Studies.

Dewulf, A., M. Crps, R. Bouwen, F. Abril, and M. Zhingri. 2005. How indigenous farmers and university engineers create actionable knowledge for sustainable irrigation. Action Research 3: 175-192.

Eshuis, J., and M. Stuver. 2005. Learning in context through conflict and alignment: Farmers and scientists in search of sustainable agriculture. Agricultural and Human Values 22: 137-148.

Goldberger, J.R. 2008. Non-governmental organizations, strategic bridge building, and the "scientization" of organic agriculture in Kenya. Agriculture and Human Values 25: 271-289.

Goodman, D. 2001. Ontology matter: The relational materiality of nature and agro-food studies. Socialogia Ruralis 41(2): 182-199.

Heffernan, C., K. Thomson, and L. Nielsen. 2008. Livestock vaccine adoption among poor farmers in Bolivia: Remembering innovation diffusion theory. Vaccine 26: 2433-2442.

Hu, R.F., Z.J. Yang, P. Kelly, and J.K. Huang. 2009. Agricultural extension system reform and agent time allocation in China. China Economic Review 20: 303-315.

Igoe, J. 2003. Scaling up civil society: Donor money, NGOs, and the pastoralist land rights movement in Tanzania. Development and Change 34(5): 836-885.

Leeuwis, C., and A.W. Van den Ban (eds.). 2004. Communication for rural innovation rethinking agricultural extension. Oxford: Blackwell, Science.

Liu, M., L.H. Wu, Y. Gao, and Y.H. Wang. 2011. Farmers' adoption of sustainable agricultural technologies: A case study in Shandong Province, China. Journal of Food and Agricultural Environment 9(2): 623-628.

Lorentzen, J. 2010. Low-income countries and innovation studies: A review of recent literature. African Journal of Science, Technology, Innovation, and Development 2(3): 46-81.

Lundvall, B.A. (ed.). 2010. National systems of innovation toward a theoretic innovation and interactive learning. London: Anthem Press.

Pant, L.P., and H.H. Odame. 2006. Multi-stakeholder deliberation on dialectical divides: An operational principle of the system of innovation. Knowledge Management for Development Journal 2(3): 60-74.

Perez-Aleman, P. 2012. Global standards and local knowledge building: Upgrading small procedures in developing countries. Proceedings of the Natural Academy of Sciences of the United States of America 109(31): 12344-12349.

Pretty, J. 1995. Regenerating agriculture: Policies and practices for sustainability and self-reliance. London: Earthscan.

Rajasekaran, B 1993. A framework for incorporating indigenous knowledge systems into agricultural research, extension and NGO's for sustainable agricultural development studies in technology and social change, report no 21, Technology and Social Change Program. Iowa State University, Iowa. Ames.

Reijnties, C., B. Haverkort, and A. Waters-Bayer. 1992. Farming for the future. An introduction to low-external input and sustainable agriculture. London: Macmillan.

Risk, S., M. Chiddambarabathan, C. Escobar, U. Wiesmann, and A. Zimmermann. 2007. Moving from sustainable management to sustainable governance of natural resources: The role of social learning processes in rural India, Bolivia, and Mali. Journal of Rural Studies 23: 23-37.

Rivera, W.M., and V. Rasheed Sulaiman. 2009. Extension: Object of reform, engine for innovation. Outlook on Agriculture 38(3): 267-273.

Rogers, E.M. 1962. Diffusion of innovation. New York: Free Press.

Röling, N.G. 1994. Platform for decision making about ecosystem. In Future of the land: Mobilizing and integrating knowledge for the land use, ed. L. Fresco, L. Stroosnijder, J. Bouma, and H. van Keulen, 386-393. Chichester: Wiley.
Röling, N.G. 1988. Extension science: Information system in agricultural development. Cambridge: Cambridge University Press.

Roux, D.J., K.H. Rogers, H.C. Biggs, P.J. Ashton, and A. Sergeant. 2006. Bridging the science-management divide: Moving from unidirectional knowledge transfer to knowledge interfacing and sharing. Ecology and Society 11(1): Article 4.

Ruttan, V.M. 1996. What happened to technology adoption-diffusion research. Sociologia Ruralis 36(1): 51-73.

Schumacher, E.F. 1973. Small is beautiful: A study of economics as if people mattered. London: Blond \& Briggs.

Schneider, F., D. Steiger, T. Ledermann, P. Fry, and S. Rist. 2012. Notillage farming: Co-creation of innovation through networking building. Land Degradation and Development 23(3): 242-255.

Scoones, I., and J. Thompson. 1994. Knowledge, power, and agriculture: Towards a theoretical understanding. In Beyond farmer first: Rural people's knowledge, agricultural research, and extension Practice, ed. I. Scoones, and J. Thompson, 16-31. London: Intermediate Technology Publication.

Sneddon, J., G. Soutear, and T. Mazzarol. 2010. Modeling the faddish, fashionable, and efficient diffusion of agricultural technologies: A case study of the diffusion of wool testing technology in Australia. Technology Forecasting and Social Change 78: 468-480.

Spielman, D. 2006. A critique of innovation systems perspectives on agricultural research in developing countries. Innovation Strategy Today 2(1): 42-55.

Wang, J.X., J.K. Huang, S. Rozelle, and Q.Q. Huang. 2009. Understanding water crisis in Northern China: What the government and farmers are doing. International Journal of Water Resources Development 25(1): 141-158.

Williams, L.D.A., and T.S. Woodson. 2012. The future of innovation studies in less economically developed countries. Minerva 50(2): 221-237.

World Bank. 2006. Enhancing agricultural innovation: How to go beyond the strengthening of research system. Washington, DC: ARD, World Bank.

World Bank. 2004. Promoting local innovation: Enhancing IK dynamics and links with scientific knowledge. IK Notes 76. http://www.worldbank.org/afri/ik/default.htm.

Wortmann, C.S., A.P. Christiansen, K.L. Glewen, T.A. Hejny, J. Mulliken, J.M. Peterson, D.L. Varner, S. Wortmann, and G.L. Zoubek. 2005. Farmer research: Conventional experiences and guidelines for alternative agriculture and multi-functional agro-ecosystems. Renewable Agriculture and Food Systems 20(4): 243-251.

$\mathrm{Wu}$, B. 2003. Sustainable development in rural China: Farmer innovation and self-organization in marginal areas. London: Routledge-Curzon.

Wu, B., and J. Pretty. 2004. Social connectedness in marginal rural China: The case of farmer innovation circles in Zhidan, north Shaanxi. Agriculture and Human Values 21: 81-92.

\section{Author Biographies}

Bin Wu, PhD, is a senior research fellow in School of Contemporary Chinese Studies, University of Nottingham. With an interdisciplinary training background, his research interests include rural sustainability and farmer innovation in China, global citizenship education, and university engagement with local community development.

Liyan Zhang, PhD, is Professor and Director of the Center for Innovation and Entrepreneurship at Tianjin University of Finance and Economics, China. Her research interest is grassroots innovation in China and India. 